\title{
MÚSCULO DIAFRAGMA HOMÓLOGO CONSERVADO EM SOLUÇÃO SUPERSATURADA DE AÇÚCAR PARA REPARAÇ̃̃O DE GRANDE DEFEITO NO DIAFRAGMA DE CÃO ${ }^{1}$
}

\author{
HOMOLOGOUS DIAPHRAGM MUSCLE CONSERVED IN SUPERSATURATED SUGAR \\ SOLUTION TO REPAR LARGE DEFECTS IN DIAPHRAGM OF DOGS
}

\author{
Alexandre Mazzanti ${ }^{2}$ Ney Luis Pippi ${ }^{3}$ Alceu Gaspar Raiser ${ }^{4}$ Dominguita Lühers Graça $^{5}$ \\ Aron Ferreira da Silveira ${ }^{6}$ Renato Xavier Faria ${ }^{2}$ Aline Souza Alves ${ }^{2}$ \\ Gentil Ferreira Gonçalves ${ }^{7}$ Rafael Stedile $^{8}$ Fabrício Arigony Braga $^{8}$
}

RESUMO

O comportamento cicatricial de um segmento muscular homólogo, conservado em solução supersaturada de açúcar a $300 \%$, foi pesquisado no músculo diafragma de cão. Foram utilizados nove cães, adultos, três machos, sem raça definida com peso variando de 10,4 a 21,0kg, separados em três grupos de igual número denominados de I, II e III. Foi criado um defeito no hemidiafragma direito na porção muscular de dimensões 9,0 $x$ $6,0 \mathrm{~cm}$, através de toracotomia no $10^{\circ}$ espaço intercostal direito para fixação do implante muscular com fio poliglactina 910 3-0, por meio de pontos de Wolff com sobreposição de bordas. Os cães foram observados por um período de 30 dias (grupo I), 75 dias (grupo II) e 120 dias (grupo III) de pós-operatório, quando foram reoperados para observação macroscópica e coleta de amostras para avaliação histológica. Foi verificado nos animais do grupo I, substituição parcial e nos grupos II e III, substituição total da porção muscular do diafragma enxertado por tecido fibrovascular, que ocluía o defeito diafragmático, sendo observado com a evolução pós-operatória, um tecido de menor espessura, quase transparente. O emprego de segmento de músculo diafragma, conservado em solução supersaturada de açúcar a $300 \%$, em temperatura ambiente, para reparação de grande defeito no músculo diafragma de cão, é substituído por uma fina camada de tecido conjuntivo fibroso.

\section{SUMMARY}

The repair induced by an homologous muscular segment conserved in 300\% supersaturated sugar solution on the diaphragmatic muscle of dogs was investigated. Nine adults mongrel dogs, three males, weights varying from 10.4 to $21.0 \mathrm{~kg}$, were used separated in three equally numbered denominated groups I, II and III. A defect was created, on the muscular portion of the right hemidiaphragm, with dimensions of $9.0 \times 6.0 \mathrm{~cm}$, through thoracotomy in the $10^{\text {th }}$ right intercostal space. The graft was sutured with thread poligalactin 910 3-0, by means of horizontal mattress suture, in an isolated pattern. The dogs were observed for a period of 30 days (subgroups I), 75 days (groups II) and 120 days (groups III) postoperatively. After this period, macroscopic observation and collection of samples for histologic evaluation were performed. It was verified in the animals of the subgroup I, partial substitution and in the subgroups II and III, total substitution of the muscular portion of the diaphragm. A fibrovascular tissue occluding the diaphragmatic defect was observed. With the postoperative evolution, a thin tissue, almost transparent, was identified. The segment of diaphragmatic muscle conserved in $300 \%$ supersaturated sugar solution, at room temperature, for repair of great defects in the diaphragmatic muscle of dogs was substituted by a fine layer of fibrous connective tissue.

Key words: implant, muscle, sugar, surgery, dog.

\footnotetext{
${ }^{1}$ Parte da dissertação de Mestrado apresentado pelo primeiro autor ao Programa de Pós-graduação em Medicina Veterinária. Universidade Federal de Santa Maria (UFSM). ${ }^{2}$ Alunos do Programa de Pós-graduação em Medicina Veterinária. UFSM.

${ }^{3}$ Professor Adjunto, PhD, Departamento de Clínica de Pequenos Animais(DCPA), UFSM

${ }^{4}$ Professor Titular, Doutor, DCPA, UFSM. Faixa de Camobi, km 9,5 - Hospital Veterinário. CEP 97105-9000. raisermv@ @ince.hcv.ufsm.br. Autor para correspondência

${ }^{5}$ Professora Titular, PhD. Departamento de Patologia. UFSM.

${ }^{6}$ Professor Titular, Mestre. Departamento de Morfologia. Centro de Ciência Rurais. UFSM.

${ }^{7}$ Professor. Mestre. Universidade Paranaense. Umuarama - PR.

${ }^{8}$ Acadêmicos do Curso de Medicina Veterinária. UFSM.
} 


\section{INTRODUÇÃO}

A hérnia diafragmática caracteriza-se pela protrusão de vísceras da cavidade abdominal para a torácica, oriunda de defeitos adquiridos ou congênitos do músculo diafragma (LIN, 1972). O traumatismo é a causa mais comum de defeito diafragmático adquirido em cães e gatos, sendo os acidentes automobilísticos, o principal agente indutor (WILSON \& HAYES, 1986). Entre os sinais clínicos mais notáveis, podem-se citar a dispnéia e intolerância ao exercício (STICKLE, 1984).

A correção cirúrgica de hérnia diafragmática, na maioria das vezes, ocorre por aproximação das bordas das feridas mediante suturas (SPEIRS \& REYNOLDS, 1976). Quando a lesão no músculo diafragma for extensa em decorrência de processos infecciosos, traumatismo ou neoplasia (SPEIRS \& REYNOLDS, 1976), ela não pode ser ocluída por primeira intenção, pois tende a ocasionar aumento da tensão na linha de sutura (JOHNSON, 1998), necessitando de procedimentos cirúrgicos mais apropriados (EURIDES et al., 1994).

Vários métodos de reparação de defeito do diafragma de cão podem ser utilizados. LATTERI et al. (1966) empregaram dura-máter homóloga e verificaram que o implante permitiu a restauração do diafragma, servindo como suporte temporário para a proliferação de tecido conjuntivo, sem demonstrar intensa reação inflamatória. GALLO et al. (1982), que testaram pericárdio de bovino e suíno conservado em solução de glutaraldeído, notaram boa vedação do defeito diafragmático, sendo histologicamente observada presença de uma camada de tecido conjuntivo sobre o implante. RODGERS et al. (1981), que utilizaram dura-máter humana esterilizada em solução de betapropiolactona a $1 \%$ e conservada em solução salina-plasma, verificaram reconstituição do diafragma, mediante a formação de fibras colágenas na área de implantação. Os autores indicaram o seu uso para reparação do diafragma, pois é bem tolerado pelo tecido receptor e mantém resistência por prolongado período de tempo.

O açúcar comum ou sacarose de cana-deaçúcar vem sendo utilizado na rotina médica para tratamento de feridas infectadas em seres humanos (SILVA et al., 1996) e animais (RAISER \& BADKE, 1987). Como características, podem-se citar seu efeito cicatrizante por participar no desenvolvimento e maturação precoce de tecido de granulação e favorecimento rápido da regeneração epitelial (PRATA et al., 1988), além do poder antimicrobiano sobre alguns tipos de bactérias, freqüentemente isoladas de feridas cirúrgicas (RAHAL et al., 1979; RAISER \& BADKE, 1987; COSTA NETO et al., 1997).

Os objetivos deste experimento foram o de estudar o comportamento do músculo diafragma homólogo conservado em solução supersaturada de açúcar a $300 \%$, quando empregado na reparação de defeito do diafragma de cão, e avaliar a capacidade da solução em conservar o implante muscular, por meio de análises clínica, macroscópica e histológica da área de implantação e de prováveis reações de rejeição.

\section{MATERIAL E MÉTODOS}

Foram utilizados nove cães, adultos, clinicamente sadios, sem raça definida, três machos e seis fêmeas, com peso variando de 10,4 a $21,0 \mathrm{~kg}$, oriundos do Biotério Central da Universidade Federal de Santa Maria e distribuídos, ao acaso, em três grupos de igual número, denominados de I, II, III. Esses animais permaneceram sob observação clínica num período de sete dias e, após serem vermifugados com albendazole ${ }^{\mathrm{a}}$ (25mg/kg de peso corporal), foram mantidos em alojamentos individuais com alimentação e água à vontade. Após jejum prévio de 12 horas, os animais foram tranquiilizados com maleato de acepromazina ${ }^{\mathrm{b}} 1 \%(0,1 \mathrm{mg} / \mathrm{kg}$ de peso corporal), via intravenosa (IV), associado a fentanil ${ }^{\mathrm{c}}$ $(0,05 \mathrm{mg} / \mathrm{kg}, \mathrm{IV})$ e tiveram a região torácica lateral direita tricotomizada. Realizou-se a indução anestésica com tiopental sódico ${ }^{\mathrm{d}} 2,5 \%(12,5 \mathrm{mg} / \mathrm{kg}$ de peso corporal, IV) e, após intubação oro-traqueal, foram mantidos sob anestesia inalatória com halotano ${ }^{\mathrm{e}}$, em plano anestésico três (GUEDEL, 1951) e ventilados por pressão positiva com oxigênio através de dispositivos Narcotop do Respirador Narcomatic ${ }^{f}$. Com a contenção dos animais em decúbito lateral esquerdo, realizou-se anti-sepsia do campo operatório com álcool-iodo-álcool.

Para a preparação da solução supersaturada de açúcar ${ }^{\mathrm{g}}$ a $300 \%$, foram utilizados 300 gramas de açúcar cristalizado em 100 mililitros de água tridestilada, obtendo-se, no final, uma solução na proporção 3:1 que foi homogeneizada. Para montagem do banco de implantes, segmentos de músculo diafragma foram obtidos de cães necropsiados no setor de patologia, sem alterações macroscópicas nessa musculatura e que não tivessem sido acometidos por doença infecto-contagiosa. Para a preparação do segmento, removeu-se todo o músculo diafragma, preservando somente a porção muscular. Em seguida, o segmento foi banhado abundantemente com solução fisiológica a $0,9 \%$ e colocado em frasco estéril contendo solução supersaturada de açúcar a $300 \%$, previamente homogeneizada. Decorridas 48 
horas, a solução foi trocada e o segmento muscular permaneceu imerso para conservação e armazenamento num período não inferior a 30 dias, em temperatura ambiente. $\mathrm{O}$ segmento de músculo diafragma homólogo foi removido do frasco com solução de açúcar 15 minutos antes do implante, irrigado abundantemente com solução salina e imerso numa cuba rim estéril, contendo solução fisiológica a $0,9 \%$, à temperatura ambiente para hidratação. O músculo diafragma homólogo foi preparado confeccionando-se um segmento de dimensões suficientes para ocluir o defeito diafragmático provocado.

$\mathrm{O}$ acesso ao músculo diafragma foi mediante toracotomia no $10^{\circ}$ espaço intercostal direito. Após a identificação do músculo diafragma e com auxílio de um lâmina radiográfica estéril de dimensões 9,0 x $6,0 \mathrm{~cm}$, demarcou-se uma área do músculo diafragma direito com quatro pontos de reparo de fio poliglactina $^{\text {h }} 910, n^{\text {o }} 3-0$ em cada ângulo do defeito. Em seguida, removeu-se com bisturi, por entre os pontos de reparo, um segmento do músculo diafragma, resultando num defeito de mesmas dimensões. O segmento de músculo diafragma homólogo foi fixado, com fio poliglactina ${ }^{\text {h }} 910 n^{\circ} 3-0$, às bordas da ferida diafragmática, utilizando-se pontos de Wolff com sobreposição de bordas de modo que os nós permanecessem sobre o face torácica do implante.

A toracorrafia foi realizada com pontos simples contínuos com fio de poliamida ${ }^{\mathrm{i}} 0,30$, sendo o de pele, com pontos simples separados com fio mononáilon $^{\mathrm{j}} \mathrm{n}^{\mathrm{o}}$ 3-0. O restabelecimento da pressão negativa intratorácica foi feito por insuflação pulmonar quando da aplicação do último ponto do primeiro plano de sutura. A insuflação do pulmão foi controlada com auxílio de uma válvula ${ }^{\mathrm{f}}$, evitando pressão intratraqueal superior a $20 \mathrm{~cm}$ de $\mathrm{H}_{2} \mathrm{O}$. A permanência de um eventual pneumotórax residual foi verificada e o ar extraído pelo terço médio do $7^{\circ}$ espaço intercostal mediante a agulha $25 \times 8$, adaptada a seringa de $60 \mathrm{~m} \ell$, por meio de torneira de 3 vias.

Foram utilizados ampicilina sódica ${ }^{\mathrm{k}}$ $(20 \mathrm{mg} / \mathrm{kg}$ de peso corporal, IV) e flunixin meglumine $^{\mathrm{l}}(1 \mathrm{mg} / \mathrm{kg}$ de peso corporal, IV), trinta minutos antes do início da cirurgia, sendo repetido o mesmo antiinflamatório, por via intramuscular, no pós-operatório durante mais dois dias. A ferida cirúrgica cutânea foi submetida a curativo local com solução salina durante 10 dias e os pontos de pele retirados com oito dias de pós-operatório. Nos períodos pré-estabelecidos para avaliação pósoperatória, os animais de cada grupo foram submetidos à eutanásia com injeção intravenosa de tiopental sódico ${ }^{c}(12,5 \mathrm{mg} / \mathrm{kg}$ de peso corporal, IV), seguido de solução de cloreto de potássio, para análise macroscópica e coleta de fragmentos para estudo em microscopia de luz da área de implantação. $\mathrm{O}$ material foi fixado em formalina a $10 \%$, por um período mínimo de dois dias e os cortes para a histologia corados pelas técnicas de hematoxilina-eosina (HE) e tricrômico de Masson (TM).

\section{RESULTADOS E DISCUSSÃO}

$\mathrm{O}$ acesso ao diafragma pelo $10^{\circ}$ espaço intercostal direito, empregado neste experimento, foi o mesmo adotado por OLIVEIRA (1998), sendo eficiente e permitindo a fixação do implante sobre o defeito no músculo diafragma, sem interferência no campo cirúrgico durante a expansão pulmonar. Outras alternativas de acesso ao músculo diafragma foram propostas, como a via tóraco-abdominal praticada por PUNCH \& SLATTER (1985), $7^{\circ}$ espaço intercostal esquerdo utilizado por GALLO et al. (1982) e LATTERI $\boldsymbol{e t}$ al. (1966), $8^{\circ}$ espaço intercostal empregado por RAISER (1994) e BARREIROS et al. (1996), 9º espaço intercostal esquerdo por DALECK et al. (1988), laparotomia mediana por LIN (1972), SWEET \& WATERS (1991), RANZANI et al. (1990) e FARIA $\boldsymbol{e} \boldsymbol{t} \boldsymbol{a l}$. (1999) e paracostal utilizado por EURIDES $\boldsymbol{e t}$ al. (1994). Já, para a realização de defeitos diafragmático com dimensões superiores às empregadas neste experimento, e com envolvimento do centro tendinoso, o acesso ao $10^{\circ}$ espaço intercostal poderá limitar a visualização e aplicação da técnica cirúrgica, pois, essa posição dificulta uma visão da cúpula diafragmática, sendo indicados outros acessos, fato também notado por OLIVEIRA (1998).

O ponto de Wolff com sobreposição de bordas foi empregado pela sua característica de ponto pneumostático, segundo o relato de NELSON (1986), o que permitiu boa vedação do defeito, suportando o restabelecimento da pressão intratorácica, durante a toracocentese para remoção do pneumotórax residual, fato também encontrado por BARREIROS et al. (1996) e OLIVEIRA (1998). Outros tipos de sutura, no entanto, podem ser empregadas como o ponto simples separado, utilizado por LATTERI et al. (1966), LIN (1972), GALLO $\boldsymbol{e}$ t al. (1982) e EURIDES et al. (1994) ou ponto simples contínuo, empregado por RANZANI et al. (1990).

O fio poliglactina 910 se mostrou resistente e de fácil manuseio, além de suportar o gradiente de pressão sobre o diafragma. Na avaliação microscópica no $30^{\circ}$ dia de pós-operatório, verificaram-se, ao redor dos filamentos componentes do fio de sutura e do implante muscular, infiltração 
discreta de polimorfonucleares neutrófilos e raros macrófagos. Na região de implantação, no entanto, onde havia ocorrido a substituição do implante por tecido fibrovascular, não foi notada ao redor do fio, infiltração de células inflamatórias, demonstrando que a reação encontrada possivelmente não foi pela presença do fio de sutura e sim pelo implante muscular, ao contrário do observado por EURIDES et al. (1994), que verificaram, no mesmo período de análise, aumento de mononucleares, sendo o resultado atribuído à presença do implante e, principalmente, do fio de sutura. BARREIROS et al. (1996), utilizando o mesmo tipo de fio, encontraram reação inflamatória discreta, com predominância de células mononucleares.

Em todos os animais dos grupos I, II e III, foram observadas aderências entre a área implantada e órgãos abdominais e torácicos adjacentes. Entre as estruturas abdominais, o fígado foi o que preponderou, quanto a aderências (88\%), fato também observado por DALECK et al. (1988), RANZANI $\boldsymbol{e}$ t al. (1990), EURIDES et al. (1994) e MATSUMOTO et al. (1996). Isso ocorreu devido ao posicionamento do defeito diafragmático na porção muscular direita e sua relação próxima com o fígado. Entre as estruturas torácicas, o pulmão $(88 \%)$ teve maior incidência, sendo também observado por LATTERI $\boldsymbol{e t}$ al. (1966), quando empregaram duramáter heteróloga para reparação de defeitos no diafragma de cão. A formação de aderências entre o implante e os órgãos abdominais e torácicos ocorreu pelo sangramento observado nas bordas do defeito diafragmático, ocasionando o extravasamento de fibrinogênio e conseqüente formação de fibrina e, também, pela presença do implante que induziu uma reação inflamatória do tipo fibroproliferativa, culminando com a formação de aderência fibrosa. Esses achados corroboram com os observados por DEL CARLO et al. (1997), no estudo de aderências peritoniais provocadas experimentalmente em cães. Apesar das aderências do segmento muscular conservado em solução supersaturada de açúcar a $300 \%$ com os órgãos abdominais e torácicos, não foi notado, durante o período de observação, comprometimento clínico das estruturas envolvidas, à semelhança dos achados de EURIDES et al. (1994). Para RODGERS et al. (1981), o desenvolvimento de um novo peritônio sobre a superfície do implante de dura-máter, minimizou a aderência com vísceras abdominais.

A evolução das lesões, quando analisadas macroscopicamente, revelou que, aos 30 dias de pósoperatório, o tecido fibrovascular, que ocluía o defeito diafragmático, era de uma espessura maior ao encontrado na área de implantação no $75^{\circ}$ e $120^{\circ}$ dias de pós-operatório (Figura 1). Isso demonstra que na área de implantação, o tecido fibroso inicialmente proliferou de forma acentuada com intuito de reconstituir, anatomicamente, o defeito diafragmático, sendo submetido, com a evolução cicatricial, a um processo de remodelação. Adicionalmente, as aderências verificadas nos animais do grupo II e III, envolvendo grande parte do lobo hepático pela cavidade abdominal e lobo pulmonar e pleura parietal costal pela cavidade torácica, podem ter impedido o músculo diafragma de sofrer uma contração efetiva durante a respiração. Com isso, a área de implantação durante a contração muscular não sofreria uma

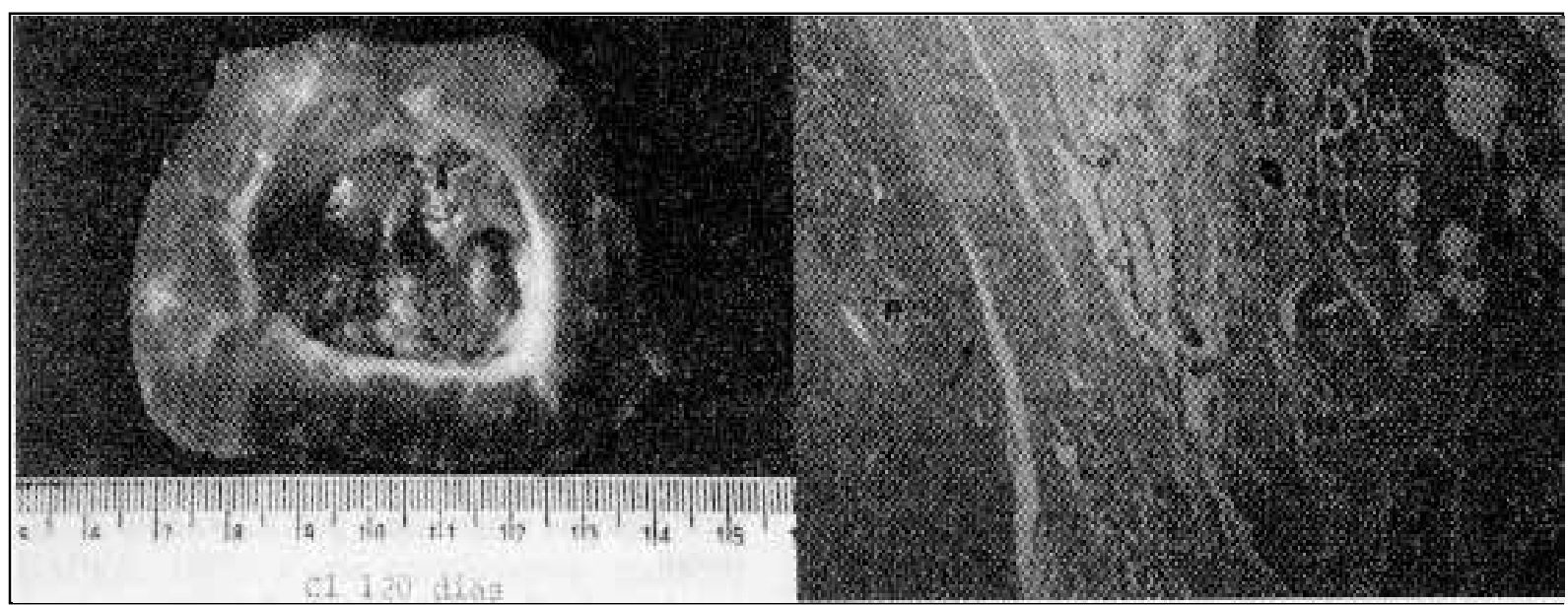

Figura 1 - Aspecto macroscópico e histológico do diafragma de cão decorridos 120 dias da implantação de um segmento muscular homólogo de diafragma. Nota-se, na face abdominal da área de implantação, fina camada de tecido fibrovascular vedando a ferida diafragmática, de coloração quase transparente. Em (A), observa-se presença de lobos pancreáticos aderidos à região do implante. Pela microscopia, verifica-se, na área de implantação e em contato com o fígado (F), tecido fibroso maduro (seta longa) e próximo ao pulmão (P), mais jovem, frouxo e vascularizado (seta curta; HE - Objetiva 4X).

Ciência Rural, v. 31, n. 2, 2001. 
tensão que poderia contribuir como um estímulo para proliferação de tecido fibrovascular durante o processo cicatricial. LATTERI et al. (1966) não verificaram alteração da dinâmica do músculo diafragma, e o tecido conjuntivo que ocluía o defeito diafragmático apresentava, decorridos 3 meses, espessura de 2 a $3 \mathrm{~mm}$, apesar da aderência discreta da área de implantação com o pulmão.

$\mathrm{Na}$ avaliação microscópica da área de implantação dos animais do grupo I, verificou-se que as fibras musculares do implante foram quase totalmente substituídas por tecido de granulação, com completa união das bordas do defeito diafragmático. Os feixes musculares do implante estavam infiltrados por uma quantidade moderada de polimorfonucleares neutrófilos. O tecido fibroso que preenchia o defeito diafragmático era constituído por, aproximadamente, $90 \%$ de fibras colágenas de coloração esverdeada, sendo o restante de coloração avermelhada. Isso demonstra que a maior parte do defeito diafragmático foi preenchida por um tecido fibroso, que sofria uma tensão moderada durante a contração muscular. Já as fibras colágenas de coloração avermelhada, componentes do tecido fibroso, demonstraram que aquela região sofria uma maior tensão quando da contração muscular diafragmática. Adicionalmente, a área de implantação voltada para a face abdominal e em contato com o fígado revelava um tecido fibroso maduro, enquanto que na face torácica e em contato com o pulmão, esse tecido era mais jovem, frouxo e vascularizado. Esse resultado pode ser atribuído à presença do tecido aderido em questão, pois, na presença do fígado e por apresentar uma cápsula fibrosa, densa, pode ter caracterizado o tecido conjuntivo que desenvolveu na região. $\mathrm{O}$ mesmo fato serve para o tecido pulmonar que apresenta uma cápsula mais elástica e frouxa, dando ao tecido conjuntivo da região esse mesmo aspecto.

Os mesmos resultados microscópicos foram observados nos grupos II e III (Figura 1), porém, com total substituição do implante de músculo diafragmático por tecido de granulação, caracterizando o processo cicatricial, como verificado por EURIDES et al. (1994), empregando segmento de peritônio-muscular para reparo de defeito de diafragma em cães. Esses resultados revelam que o implante muscular conservado foi substituído por tecido de granulação, indicando que o implante se comportou como estrutura de sustentação temporária sendo substituído progressivamente. RANZANI et al. (1990) observaram que, decorridos 60 dias da implantação no músculo diafragma de cão, o implante de pericárdio de eqüino, conservado em solução de glicerina a $98 \%$, havia sido totalmente substituído por uma membrana de tecido conjuntivo fibroso. Já BARREIROS et al. (1996) notaram, no $30^{\circ}$ dia de pós-operatório, que o implante muscular autólogo para reparação de diafragma de cão, apresentava aspecto de tecido fibroso fascicular. RODGERS $\boldsymbol{e t}$ al. (1981) verificaram tal ocorrência com dura-máter humana decorridos 6 meses de implantação. A preparação prévia desses implantes e sua conservação em diferentes soluções associadas à estrutura morfológica dos implantes podem ter contribuído para essa variação no tempo de substituição por tecido conjuntivo fibroso.

$\mathrm{O}$ uso de implante muscular de diafragma de cão mostrou-se, durante a evolução cicatricial, ser substituído por tecido conjuntivo fibroso e não ocasionar sinais clínicos de infecção e rejeição no tecido receptor, fato também verificado por LATTERI $\boldsymbol{e} t$ al. (1966), quando utilizaram dura-máter de cão, GALLO et al. (1982) com o pericárdio de bovino e suíno, HUTSON \& AZMY (1985) com dura-máter humana, DALECK $\boldsymbol{e t}$ al. (1988) com peritônio de bovino, RANZANI et al. (1990) com pericárdio de eqüino e MATSUMOTO et al. (1996) com pericárdio de cão. Além disso, o emprego de materiais biológicos livres e conservados por longos períodos revelaram inúmeras vantagens, à semelhança das citadas por RODGERS et al. (1981), como a de manter a resistência da área implantada, permitir a incorporação ou substituição pelo tecido receptor, serem resistentes a infecções e terem a possibilidade de ser moldados de acordo com o defeito diafragmático.

A conservação do segmento de músculo diafragma, em solução supersaturada de açúcar a $300 \%$, manteve aparente resistência do implante com manutenção das estruturas morfológicas do implante, coincidindo com os achados de MAZZANTI et al. (1999), quando utilizaram a mesma solução para conservação de músculo diafragma de cão. Resultados semelhantes foram encontrados por RODGERS et al. (1981) com solução de betapropiolactona a $1 \%$ e salina, GALLO et al. (1982) com solução de glutaraldeído, MATSUMOTO et al. (1996) com solução de Denacol, PIGOSSI et al. (1971), DALECK $\boldsymbol{e t}$ al. (1988) e RANZANI et al. (1990), com solução de glicerina a 98\%. Devido a sua aplicação no tratamento de feridas, tanto na rotina médica em indivíduos da espécie humana, salientado por SILVA et al. (1996) e em animal por RAISER \& BADKE (1987), o interesse pela utilização do açúcar para conservação de tecidos deveu-se às suas propriedades, relatadas por WEISS et al. (1984) e COSTA NETO (1997). Apesar de não terem sido realizados estudos microbiológicos da solução 
conservante de açúcar, não foram detectados, sinais de infecção, à semelhança do observado por LATTERI et al. (1966), GALLO et al. (1982), DALECK $\boldsymbol{e}$ t al. (1988) e RANZANI $\boldsymbol{e t}$ al. (1990), quando empregaram outras soluções conservantes. Esse resultado pode ser atribuído às propriedades antimicrobianas do açúcar, estudadas por RAHAL $\boldsymbol{e t}$ al. (1979), RAISER \& BADKE (1987) e COSTA NETO et al. (1997). A conservação da porção muscular do diafragma ocorreu pelo efeito desidratante da solução supersaturada de açúcar, semelhante ao observado por PIGOSSI et al. (1971), utilizando a glicerina a $98 \%$ na conservação de duramáter de seres humanos. Esse resultado pode ser atribuído ao alto poder higroscópico do açúcar (WEISS et al., 1984).

\section{CONCLUSÕES}

O segmento de músculo diafragma mantido em solução supersaturada de açúcar a $300 \%$, em temperatura ambiente, por um período não inferior a 30 dias, conserva sua estrutura e não induz reações de rejeição pelo tecido receptor, quando utilizado como homoimplante. Estão indicados estudos complementares sobre a resistência da área de implantação e da dinâminca do diafragma, no receptor, para indicação definitiva do homoimplante ortotópico na reparação de grande defeito diafragmático no cão.

\section{FONTES DE AQUISIÇÃO}

${ }^{a}$ Albendazol. Laboratório Teuto Ltda. Anápolis, GO

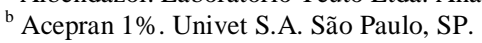

${ }^{\mathrm{c}}$ Fentanil. Janssen. São José dos Campos, SP.

d Thionembutal. Abott Laboratório do Brasil. São Paulo, SP.

${ }^{\mathrm{e}}$ Halotane.Cristália do Brasil. São Paulo, SP.

${ }^{\mathrm{f}}$ Narcomatic 2000. Narcosul S.A. Porto Alegre, RS.

${ }^{g}$ Açúcar Cristal Peneirado. Copersucar. São Paulo, SP.

${ }^{\text {h }}$ Vycril 3-0. Ethicon. Johnson \& Johnson. São José dos Campos, SP.

${ }^{i}$ Fio de Nylon Grilon. Indústria Nacional de Plásticos, SP.

j Mononylon 3-0. Ethicon. Johnson \& Johnson. São José dos Campos, SP

k Ampicilina sódica Ariston. Ariston Indústria Química. São Paulo, SP.

${ }^{1}$ Banamine. Schering-Plough. Rio de Janeiro, RJ.

\section{REFERÊNCIAS BIBLIOGRÁFICAS}

BARREIROS, L.J., RODASKI, S., SUSKO, I., et al. C. Uso experimental do músculo grande dorsal autólogo na reparação dos grandes defeitos diafragmáticos no cão. Revista do Setor de Ciências Agrárias, v.15, n.1, p.141-150, 1996.

COSTA NETO, A.A.C., PAES, J.L.L., CARVALHO, R.G., $\boldsymbol{e}$ t al Concentração bactericida do açúcar em culturas de Escherichia coli. Revista Colegio Brasileiro Cirurgia, v.24, n.3, p.151-154, 1997.
DALECK, C.R., DALECK, C.L.M., ALESSI, A.C., $\boldsymbol{e} t \boldsymbol{a l}$. Substituição de um retalho diafragmático de cão por peritônio de bovino conservado em glicerina: estudo experimental. Ars Veterinaria, v.4, n.1, p.53-61, 1988.

DEL CARLO, R.J., GALVÃO, S.R., TINTO, J.J.R., et al. Estudo macroscópico das aderências peritoneais provocadas experimentalmente em cães. Ciência Rural, v.27, n.2, p.273278, 1997.

EURIDES, D., NIGRO, A.J.T., GOLDENBERG, S., $\boldsymbol{e} \boldsymbol{t} \boldsymbol{a l}$ Reparo de defeito provocado no diafragma de cães com segmento livre peritônio-muscular. estudo experimental. Acta Cirurgica Brasileira, v.9, n.3., p.131-135, 1994.

FARIA, R.X. Transposição do músculo reto do abdome para correção de defeito iatrogênico no diafragma em cães. Santa Maria, 1999. 32p. Dissertação (Mestrado em Medicina Veterinária) - Programa de Pós-graduação em Medicina Veterinária, Universidade Federal de Santa Maria, 1999.

GALLO, J.I., ARTIÑANO, E., VAL, F., et al. Glutaraldehydepreserved heterologous pericardium for the repair of diaphragmatic defects. Journal Thoracic Cardiovascular Surgery, v.83, n.6, p.905-908, 1982.

GUEDEL, A.E. Inhalation anesthesia. 2. ed. MacMillan : New York, 1951 .

HUTSON, J.M., AZMY, A.F. Preserved dura and pericardium for closure of large abdominal wall and diaphragmatic defects in children. Annals Royal College Surgeons England, v.67, n.2, p.107-108, 1985 .

JOHNSON, K.A. Hérnia diafragmática, pericárdica e hiatal. In: SLATTER, D. Manual de cirurgia de pequenos animais. São Paulo : Manole, 1998. Cap.37, p.559-577.

LATTERI, S., ROMEO, G., DI BENEDETTO, A., $\boldsymbol{e}$ t al. Ricerche sperimentali sulla riparazioni di diffetti diaframmatici con dura madre. Gionarle Italiano Chirurgia, v.22, n.02, p.171-196, 1966

LIN, A.C. Closure of diaphragmatic defect by gut segment transplantation in dogs. Memoirs College Agriculture, v.13, n.1, p.190-195, 1972 .

MATSUMOTO, H., OGUCHI, Y., MIYAKE, Y., $\boldsymbol{e}$ t al. The use of epoxy patch grafts for repair of experimentally-created diaphragmatic defects in dogs. Journal Veterinary Medical Science, v.58, n.7, p.685-687, 1996

MAZZANTI, A., RAISER, A.G., PIPPI, N.L., et al. Avaliação histológica do músculo diafragma de cão preservado em solução supersaturada de açúcar a $300 \%$. In: CONGRESSO ESTADUAL DE MEDICINA VETERINÁRIA, 14 CONGRESSO DE MEDICINA VETERINÁRIA DO CONE SUL, 3, EXPOSIÇÃO DE PRODUTOS E SERVIÇOS EM MEDICINA VETERINÁRIA, 7 1999, Gramado, RS. Anais... Porto Alegre : SOVERGS. 1999. v.1, 375p. p.245.

NELSON, A.W. Brônquios e pulmões. In: BOJRAB, J. Cirurgia dos pequenos animais. São Paulo : Roca, 1986. Cap.20, p.295-306.

OLIVEIRA, L.O. Retalho pediculado do músculo grande dorsal para reparo de defeito diafragmático em cães. Santa Maria : Programa de Pós-graduação em Medicina Veterinária, Universidade Federal de Santa Maria, 1998. 15p. (Seminário). 
PIGOSSI, N., RAIA, A., LEX, A., et al. Estudo experimental sobre o emprego, como implante, da dura-máter homógena conservada em glicerina à temperatura ambiente. Revista Associação Medica Brasileira, v.17, n.8, p.263-278, 1971.

PRATA, M.B., HADDAD, C.M., GOLDENBERG, S., et al. Uso tópico do açúcar em ferida cutânea. Estudo experimental em rato. Acta Cirurgica Brasileira, v.3, n.2, p.43-48, 1988.

PUNCH, P.I., SLATTER, D.H. Diaphragmatic hernias. In: SLATTER, D.H. Textbook of small animal surgery. Philadelphia : Saunders, 1985. Cap.59, p.869-885.

RAHAL, F., MIMICA, I., PEREIRA, A., et al. O açúcar no tratamento local das infecções das feridas operatórias e dos abscessos intracavitários. Revista Paulista Medicina., v.94, n.1, p.132-133, 1979.

RAISER, A.G. Herniorrafia diafragmática em cães e gatos. Relato de 22 casos e proposição de técnica para corrigir rupturas freno-costais. Brazilian Journal Veterinary Research Animal Science, v.31, n.3/4, p.245-251, 1994.

RAISER, A.G., BADKE, M.R. Terapia de infecções cirúrgicas com jatos de solução salina e açúcar granulado. Revista Brasileira Medicina Veterinária, v.9, n.6, p.125-128, 1987.

RANZANI, J.J.T., GANDOLFI, W., FRANCO, M., et al Implante de pericárdio de eqüino em glicerina em solução de continuidade do diafragma de cão. Brazilian Journal Veterinary Research Animal Science, v.27, n.01, p.65-73, 1990.
RODGERS, B.M., MAHER, J.W., TALBERT, J.L. The use of preserved human dura for closure of abdominal wall and diaphragmatic defects. Annals Surgery, v.193, n.5, p.606$611,1981$.

SILVA, S.V., QUESSADA, A.M., SILVA, F.L., et al. Açúcar na cicatrização de ferida infectada em eqüino. Revista Brasileira Medicina Veterinaria, v.18, n.2, p.84, 1996.

SPEIRS, V.C., REYNOLDS, W.T. Sucessful repair of a diaphragmatic hernia in a foal. Equine Veterinary Journal, v.8, n.01, p.170-172, 1976.

STICKLE, R.L. Positive-contrast celiography (peritoneography) for the diagnosis of diaphragmatic hernia in dogs and cats. Journal American Veterinary Medical Association, v.185, n.3, p.295-298, 1984.

SWEET, D.C., WATERS, D.J. Role of surgery in the management of dogs with pathologic conditions of the thorax - part II. Compendium Continuing Education Practicing Veterinarian, v.13, n.11, p.1671-1677, 1991.

WEISS, R.G., NECTOUX FILHO, J.L., FALLEIRO, R.P.T., $\boldsymbol{e}$ al. Tratamento da ferida operatória infectada: açúcar, uma nova opção. Revista AMRIGS, v.28, n.4, p.337-342, 1984.

WILSON, G.P., HAYES, H.M. Diaphragmatic hernia in the dog and cat: a 25-year overview. Seminars Veterinary Medicine Surgery (Small Animals), v.1, n.3, p.318-326, 1986.

Ciência Rural, v. 31, n. 2, 2001. 